\title{
Aspects of Writing the Textbooks of the Albanian People History in Pre-University Education
}

\author{
Dr. Esilda Luku \\ Department of Political Sciences, Faculty of Political Sciences and Law \\ University "Aleksandër Moisiu", Durrës, Albania \\ Email: esildaluku@yahoo.com
}

Doi:10.5901/jesr.2014.v4n4p466

\begin{abstract}
This paper aims to analyse the challenges of historiography, in particular those coming across during the process of writing the textbooks of history for the educational curriculum. Its approach is theoretical as much as empirical. The object of the paper is to evaluate the level of meeting the scientific criteria in the text "The history of the albanian people 12". Considering the fact that historical literature, including the school books of history, is written continuously, historians should meet the following criteria: 1. The generalising criterion, meaning the synthetic presentation of historical processes treated with a scientific objectivity. During the compilation, it is necessary to avoid biased stance, politicisation and extreme ideological arguments that distort the historical truth. Scientific accuracy can be reached by using the valid thesis of native and foreign historiography. 2. The chronological criterion, as the main characteristic of the historicism, implies time arrangement of historical events. It intends to analyse in right proportion the historical periods, in conformity with the most accepted periodisation of this scientific discipline. 3. The psychopedagogic criterion is based on the adaptation of the formative and informative material with the psychological and intellectual qualities, as well as the perceiving and assimilating abilities of the reader. The accurate meeting of these scientific criteria leads the historian's work during the process of research and the interpretation of the sources. These last ones require the research methods of analysis (deduction) and synthesis (induction), as well as the methods of synchronic and dychronic analogy. The analytic approach of the historical facts and events influences on the development of the critical thinking and the scientific content of history as discipline, that begins with the compilation of the school textbooks of preliminary and high educational system.
\end{abstract}

Keywords: historiography, scientific criteria, history textbooks, curriculum, "The history of albanian people 12".

\section{Introduction}

"History is always written wrong and so, always needs to be rewritten" (Bacelli, 2007: 9). This quote of the SpanishAmerican philosopher, George Santayana, proclaims the permanent challenge of the historical science on the necessity of writing history textbooks, in accordance with the respective scientific criteria. This objective derives from the development in time and space of the historical events, as well as the new way of perception, classification, evaluation and interpretation of sources.

\section{The Writing of History Textbooks for the Educational Curriculum}

The subject of History in the school curriculum occupies an important place in all stages of the pre-university education system. Its study aims to recognize, chronologically, the main multidisciplinary experiences of specific societies and their contribution to world civilization; the development of critical thinking and the use of acquired knowledge to build a progressive future. The purpose of history is to "know the past in order to understand the present, thus the historical knowledge helps to prepare the future citizen as an active member of the democratic society. These goals are achieved when the national history is known in reality and objectively, and when it is considered as an integral part of the history of other people of the region, Europe and the world" (Kuri \& Gjini, 2008: 81).

Based on the above mentioned function of history as a discipline, there is a need to develop the educational literature in full conformity with the historical method. The last is defined as a systematic set of principles and rules that effectively help in the collection of source materials of history, in their scientific evaluation and the presentation of the synthesis of the obtained results (Mema, 2005: 10).

The application of the historical method consists of three phases.

1) The process of finding and gathering information used as source materials. The historian and the historical fact are connected between them and by a mutual dependency. The historian without the historical fact has no 
root, but the facts without the historian are dead and meaningless (Çaushi, 2003: 12). Consequently, the first main condition of the study and the scientific research is recognition throughout the information processing, achieving a certain mastery of the material, thus owing the fundamental facts and the historical and geographical circumstances. The prior selection is essential on the basis of possession of ad hoc knowledge (with a particular purpose) (Höflechner, Hoxha \& Gurakuqi, 2005: 43).

2) The acquisition of sources meaning the achievement of historical knowledge. It implies the critical organization of search results during a given period of time. So, "the representation and the recognition of the past improve the reflection, the quality of our activity and enable us to overcome the immediate conditioned reactions and move to work of higher value. The historical knowledge does not always mean an increase of the objective knowledge in a narrow sense, but often "just" develop higher-level thinking and problem solving". (Höflechner et al., 21)

The accurate and full recognition of the past is a result of historical criticism that represents a rational art derived from methodical practice of some intellectual abilities. According to Michael Levassor, the critical analysis is a consequence of "historical skepticism", which means "that human justice does not depend on easily belief, but how to doubt in many meetings". Even the word "criticism", used to show only a judgment of taste, refers to the test of truth (Bloch, 2003: 90).

3) The formal statement of findings which includes the collection of historical data and their representation in terms of the objective truth. Objectivity in history relates to the assertion of the past reality and the truth as a matter of this corresponding reality, a clear separation between the knower and the known, fact and value, and, above all, between history and fiction. The historical facts should be considered as primary and independent of interpretation. The truth must be found within history and not be outsourced. Formally, the historical objectivity requires a description or analysis of the events treated as objects and not influenced by the subject. This idea is consistent with the epistemological cognitive subject, which recognizes the object. In practice, when we talk about objectivity we consider two meanings: one is empirical, i.e., compliance with reality. The other is rational, i.e., important to every reasonable person (Sinani, 1999: 181).

History, as a scientific discipline, aims to achieve the maximum objectivity, but not the absolute truth. This is explained by the fact that the historian, during the writing of history, which treats the activity of the human society in a multidimensional aspect and in chronological order, is inevitably influenced by the rational and emotional factors. "If the universe where people lived a long time ago had nothing in common with the universe I live, if these "two universe", marveling at a certain degree of abstraction, did not look like the same topic, then the universe of another would seem to me as foreign and would lose all meaning" (Aron, 2005: 163).

The historian tries to analyze the historical context, identify the causes and the consequences, aimed at not allowing that moral opinions on the character and the actions of the individuals determine his scientific research. Otherwise, the secondary historical facts would be given a great importance due to the subjective and psychological reasons. "As historians, we should reserve the judgment, neither praise nor condemn, because the data are never sufficient and the defendant looks like swimmer in rip current, who cannot rescue" (Berlin, 2003: 171).

In this viewpoint, the task of the historian is not to resemble a judge, but the investigator, who represents "the evidence" for the reader and creates the opportunity to extract relevant conclusions. In the textbook of History of Albanian people for high school student, the events that occurred in the year 1997 are described as "a communist rebellion". Citing: "The opposition used the descent into anarchy triggered by the pyramid schemes' collapse and managed to organize the communist rebellion of 1997. In a short time, the armories crashed and the order broke causing dramatic consequences. Only a small part of the country remained under the influence of government". (Meta, Dezhgiu \& Lleshi, 2009: 361)

According to Prof. Valentina Duka, the historians should have better described the event without giving their opinion, but by presenting the positions of the political forces on the issue. "It seems right to me, if the historians would say that the right wing considered it a communist rebellion, while the left called a movement against the pyramids" (Kuçaj, 2009: 2).

Although the historian is guided by the principle of scientific objectivity in writing the historical literature, he cannot avoid completely subjective perspective, conditioned by the lack of sufficient resources, professional skills and psychoemotional state. "... however impartial, clear, accurate, devoid of passions and able to imagine themselves in the place of others, the historian will face an entangled net of people's fates that his ignorance about them will be greater than his knowledge and, consequently, his judgments, especially evaluative judgments, will always be based on insufficient data" (Berlin, 2003: 173). "In fact, objectivity ... is subjective, is relative in the sense that varies in time and from place to place; truthfulness, reliability and insight intuitive achievements of an era, which has been fruitful in the field of knowledge, are 
only relatively, in comparison with its "climate of ideas", nothing is eternal, everything flows" (Berlin, 2003: 186).

Besides the scientific analysis and generalization, the history textbooks should be designed in accordance with the chronological criteria. The latter means taking into account the principle of historicism, which views the development of human society chronologically and in concrete. Without the dimension of time and chronology, the discipline of history would lose its contacts. It is not enough to respect the chronology, i.e., simply treat the process by the course of its history, but is also necessary to reveal links between them. While the notion of time is a condition of the complexity of the historical facts and events, it is the plasma where the phenomena are established and the place they are settled (Xhelili, 2001: 29).

The scientific studies must take into consideration the right proportion between periods, based on the acceptable periodization of the historiography. But the observation of history school manuals shows the trend of giving priority to the present. Specifically, in the textbook "History of the Albanian people 12", the analysis of the historical periods is as follows: 1. Ancient History (Antiquity) corresponds with Chapter I, "Illyrians" (pp. 7-33) 2. Albanian Middle Ages treated in Chapters II - VI, respectively "Albania under the Byzantine Empire" - "Culture and religion in Albania in XVI-XVII centuries" (pp. 34-113) 3. National Renaissance included Chapters VII - X, namely "The first stage of the National Renaissance" - "Towards the Independence of Albania (1908-1912)", (pp. 114-166) 4. Contemporary history analyzed in Chapters XI - XXII, with these topics "The Albanian people in the years 1912-1914" - "The Albanian people in the postcommunist period (1991-2008)", (pp. 167-374) (Meta et al., 5-6).

Apart from the chronological order and the analyses in proportion of the historical periods, the compilation of textbooks should fulfill the psycho-pedagogical criteria. It refers to the adjustment of the program with the psychological, intellectual, conceptual characteristics and the formation of school age students. The education material should adapt to their perceptual skills and assimilation. The information described in the textbooks need to be well structured, from the easy to the most difficult, ensure continuity and consistency. Also, it is important to avoid the overloading, the overlapping and the unnecessary duplication of the content (Kuri \& Gjini, 2008: 91).

Therefore, the main didactic demand for the design of history school books is considered the completion with the pedagogical apparatus. The latter means the structure, the language used, and the overall presentation of the education material should be in accordance with the scientific method of writing the subject. The theoretical framework is completed with maps, sketches and tables, which are functional and of high artistic and technical quality. However, the graphic designs in the textbooks do not always coincide with the information provided. For example, in the text of History of the Albanian people for the pre-university education, the chapter which analyzes the division of the Roman Empire, A. D. 395, into the Western Roman Empire and the Eastern part centered in Byzantium (Constantinople), and the inclusion of southern Illyrian territories under the Byzantine Empire, maintaining the previous administrative separation of the state in four provinces, such as: Dardania, Prevalitania, Old Epirus and New Epirus, with their respective metropolises Skopje, Scodra, Durrachium and Nicopoli, is given an incorrect illustration with a map that shows the new administrative organization of the Albanian lands in themes, in the XI century, as that of Durrachium, Nicopolis, Dalmatia, Thessaloniki and, later, the Skopje one (Meta et al., 34, 48).

In the process of textbook writing, except the necessity of respecting rigorously the scientific and the pedagogical criteria, the historians pay attention particularly to the methodology used, i.e., the ratio between the narrative (description in detail, chronologically of the historical facts and events) and analysis (which means presenting a logical and reasonable argumentation about the actors and the historical factors). In this dichotomy "historical content - interpretive skills" (Shehu, 2009: 15), the historiography emphasizes the development of the historical thinking, so the scientific rationalism. It points out the cause and effect relationship to analyze the historical events, as a means of historical knowledge with the purpose of gaining critical consciousness.

"...every written material of the past must have the beginning and the end, the cause-effect explanation, the form and the content. Only in this way it is accessible to the human mind". (Çaushi, 2003: 181) E.g., to admit the rebellion of 1997 was communist, it should be clarified in what sense. Was it a strategy to restore the communist dictatorship? It is far from the imagination. Was it a communist revenge against the democratic government? It is unknown to what extent. Did the former communists organize it? Perhaps, but it must be proven. Regarding the violation of the state institutions, it was obviously a tactic like that of the communist revolutions. But it should be explained; otherwise it remains confused (Fuga, 2009: 28).

In terms of the need for an analytical perspective on the literature, history is not a chronicle, thus a collection of facts without interpretation or the representation of unprocessed documents. On the contrary, the writing of history requires a critical reflection on all categories of sources because the interpretation is considered the main task of the historicist thinking, so the knowledge of the past helps foresee the future. Hence, the interpretation of history based on "theories that represent the fate of nations and society as a result of decisive influence of the prominent individuals, or, 
not simply as a consequence of the wishes and intentions of certain individuals, but of many people, specifying that these collective desires and purposes are determined not wholly or mainly of impersonal factors" (Berlin, 2003: 131).

During the communist regime in Albania (1945-1990), the content of school literature was influenced by the ideology. Especially, the textbooks of history served as effective instruments to help the leading class keep the power. Their analytical presentation of the mass' role and of the historical personalities deliberated considerable distortions. "Thus, in many events the role of the masses is glorified and the historical figures who have been the protagonists are forgotten. In world history, particularly the national, the historical figures are scarce in numbers due to the extreme politicization". (Xhelili, 2001: 32)

However, history as a scientific discipline aims to provide a balanced stance, neither over- nor underestimating the influence of individual-mass elements in the construction of the historical events. The objective analysis of the contribution of the participating actors is reflected on Tolstoy's historicism. The latter is a reaction against the method of writing history, which accepts, without saying openly, as true the principle of leadership. This method ascribes to the great man, the leader too many things. Tolstoy tries to show the little impact on the activity of Napoleon, Alexander etc., concerning what might be called the logic of events. The author points out "the very importance of the neglected decisions and actions of the countless and unknown individuals, who fought in the battles, set fire to Moscow and invented the partisan warfare. Historicism ... of Tolstoy's version combines the methodological individualism and collectivism, i.e., it represents the more characteristic combination, typical of his time, and I fear for our time, between the democratic individualist elements and the nationalist collectivist ones" (Popper, 2003: 145).

Referring to the historiography, scholars also argue about the degree of respecting the scientific criteria when writing the contemporary period. "No one can judge the history, if he has experienced it himself (Goethe)" (Höflechner et al., 16). "Everyone who confines the actuality to the present will not understand it, because the actuality cannot be fully explained, if not from a distance" (Bloch, 2003: 47-51). According to Prof. Valentina Duka, "the historian can discuss about the day event, but he can reach out to the historical truth after analyzing the primary documents, which are found in the archives. Once he has gathered the material from various sources, the historian has all the possibilities to do a scientific analysis of the historical events". (Bargjo, 2009: 4)

The theoretical aspect of the difference between history and memory is described by the French Professor, Pierre Nora. Regarding him, memory is the life of alive people, always in evolution, open to the dialectic of memory and forgetfulness, unconscious about the strains, fragile against the instrumentation and manipulation, able to sleep long and awake unexpectedly. While history is the problematic and the incomplete reconstruction of what is not. History is an intellectual and secular operation, which requires the analysis and the critical discourse. But, memory gives remembrance a sacred value. Pierre Nora argues that history is perpetually suspicious of memory; its real mission is to remove the memory and deconstruct it (Lubonja, 2007: 7).

The above viewpoint is also supported by Prof. Arben Puto, when analyzing the description of the events after 1990s in the textbook "History of the Albanian people 12". According to him, the present is a historical period, which is impossible to be written due to the contemporariness and the lack of documents. He said that historians must rely on accurate sources, authentic ones and not just the press. It is not recommended the writing of history in between events. Historians need to respect the principle of objective distance, which if not implemented leads to biased positions. Referring to the fact that writing the contemporary history is impossible without the citation of archival documents, based on the law setting the terms of documents use rights, but also because of dealing with current events and alive characters who are politically and socially active (Mile, 2009b: 6), as for example, the tragedy of the Gërdec, the issue of Damir Fazllic or the Durrës - Kukës highway (Shkëmbi, 2009: 6). Consequently, there is an interference of the political terminology of the day in writing the history of the post-communist period (Mile, 2009a: 2).

The philosopher Artan Fuga (2009) emphasizes that politics has no legitimacy to judge what is a historical truth or a lie. The political speech cannot undertake the scientific discourse, much less replace it. The politics may not be positive; it can interfere in the administration of the school political strategies and culture, but not producing the scientific content itself, taking into consideration that doing so risks the imposition in an authoritarian and aggressive manner on the freedom of expression and the academic freedom. Politician's mastery is finding the mechanisms to convey the political messages and the truth.

In this sense, it is imperative that during the scientific work the historian avoid at all costs the use of the political rhetoric, which "transforms the historic narrative into an ideological weapon" (Vehbiu, 2007: 15). The last violates the scientific character of history as a discipline and the professional integrity of the researchers. Regarding Prof. Rexhep Qosja, "no one can be a good historian, an important one for the history of his people, if the methodological knowledge, the historical culture and the creativity do not support the ethical principles". (Peci, 2009: 15)

Sentences such as: "In the 2001 general elections the Socialists came to power again. Their governing was 
characterized by a wave of unprecedented corruption, trafficking and uncertainty, although Albania had started the way towards the North Atlantic Treaty Organization and the Stabilization and Association Agreement towards the European Union integration". "Due to this situation, the Democratic Party won the elections in 2005 and its leader Sali Berisha came back to power. He presented the projects to fight corruption, combat the organized crime and the political program of rapid economic growth which announced a new era for development" (Meta et al., 362).

The mentioned analyses carry out obviously political bias stances that are contrary to the scientific principles of writing the historical works, especially the school literature. For that reason, it is necessary that "textbooks, owing the pedagogical continuity of normal science, should be rewritten in whole or part whenever the language, the structure problems or the standards of normal science change" (Kalemaj, 2009: 15).

This fact highlights an essential feature of historiography as science, that of constantly rewriting the history. The study and the construction of the past remain unfinished because the evaluation criteria of the historical facts change over time. Max Weber ascertained the existence of sciences, which eternal youth is reasonable and these are all the historical disciplines, which eternal flow of culture always brings new problems. Basically their task is the inevitability of new construction, typically ideal. Thus, history is a process of constant renewal and expansion because of the occurrence of past events, increased by the events of the subsequent eras, new understandings and so "each generation writes its own history anew". Therefore, "history is open to the future" (Höflechner et al., 19-20).

\section{Conclusions}

In conclusion, we mention that the writing of history textbooks for the pre-university education curriculum should be based on the respect of the historical method. It refers to the process of establishing general facts and principles giving attention to the chronological and the psycho-pedagogic criteria.

The historians should take into consideration the following issues in the process of writing, such as: the possession of their own biases and prejudicial attitudes, the existence of many factors that contribute to the historical events and the examination of the evidence not only from a singular viewpoint.

The accurate meeting of the scientific criteria and the use of the historical method serve as a guarantee for the historians to achieve reliable results in writing the textbooks of history aimed at contributing to the high quality education of the new generation.

\section{References}

Aron, R. (2005). The opium of the intellectuals. Tirana: Dituria.

Bacelli, A. (2007). "The historical truth and how to approach it". Tirana Observer, no. 229, Friday, September 28, 2007, p. 9.

Bargjo, V. (2009). "Duka: The textbook of history, is violated the professional integrity". Shekulli, Monday, September 28, 2009 , p. 4.

Berlin, I. (2003). Four essays on liberty. Tirana: Onufri.

Bloch, M. (2003). The historian's craft. Tirana: Shtëpia e Librit dhe e Komunikimit.

Çaushi, I. (2003). The methodology of history. Tirana: SHBLU.

Fuga, A. (2009). "Political influence on a textbook". Standard, Saturday, September 26, 2009, p. 28.

Höflechner, W., Hoxha, G. \& Gurakuqi, R. (2004). Introduction to the study of history. Shkodër: Phoenix Shkodra.

Kalemaj, I. (2009). "History as a political project". Shekulli, Wednesday, October 7, 2009, p. 15.

Kuçaj, K. (2009). "Duka: Historians not to violate the academic freedom". Korrieri, Thursday, September 2, 2009, p. 2.

Kuri, V. \& Gjini, R. (2008). The theoretical basis and practices of learning history. Tirana: SHBLU.

Lubonja, F. (2007). "Memory and history". Korrieri, No. 259, Thursday, September 25, 2007, p. 7.

Mema, B. (2005). Research knowledge in the field of history. Tirana: SHBLU.

Meta, B., Dezhgiu, M. \& Lleshi, Xh. (2009). History of Albanian people 12. Tirana: Uegen.

Mile, A. (2009b). "Arben Puto: It takes time to analyze the events of 1997". Panorama, Tuesday, September 29, 2009, p. 6.

Mile, A. (2009a). "Dezhgiu: We are not afraid of the truth, the events of 1997 relates to the opposition". Panorama, Thursday 24, 2009, p. 2.

Peci, A. (2009). "Rexhep Qosja: What is behind the scandal of the history of Albanians?". Gazeta Shqiptare, Thursday, October 8, 2009, p. 15.

Popper, K. (2003). The poverty of historicism. Tirana: Onufri.

Sinani, Gj. (1999). Introduction to the philosophy of history. Tirana: SHBLU.

Shehu, H. A. (2009). "History in the optic of pseudoscientists". Shekulli, Tuesday, October 6, 2009, p. 15.

Shkëmbi, A. (2009). "Godo: The history needs to be corrected; 1997 was not a communist rebellion". Panorama, Friday, September 25, 2009, p. 6.

Xhelili, Q. (2001). Didactics of history. Tirana: SHBLU.

Vehbiu, A. (2007). "History as Kitsch". Shekulli. No. 2033, Wednesday, August 29, 2007, p. 15. 